\title{
Cigarette smoke induces epithelial to mesenchymal transition and increases the metastatic ability of breast cancer cells
}

Francescopaolo Di Cello ${ }^{1}$, V Lynn Flowers ${ }^{1}$, Huili Li ${ }^{1}$, Briana Vecchio-Pagán ${ }^{1}$, Brent Gordon ${ }^{1}$, Kirsten Harbom ${ }^{1}$, James Shin ${ }^{1}$, Robert Beaty ${ }^{1}$, Wei Wang ${ }^{1}$, Cory Brayton², Stephen B Baylin ${ }^{1}$ and Cynthia A Zahnow ${ }^{1 *}$

\begin{abstract}
Background: Recent epidemiological studies demonstrate that both active and involuntary exposure to tobacco smoke increase the risk of breast cancer. Little is known, however, about the molecular mechanisms by which continuous, long term exposure to tobacco smoke contributes to breast carcinogenesis because most previous studies have focused on short term treatment models. In this work we have set out to investigate the progressive transforming effects of tobacco smoke on non-tumorigenic mammary epithelial cells and breast cancer cells using in vitro and in vivo models of chronic cigarette smoke exposure.

Results: We show that both non-tumorigenic (MCF 10A, MCF-12A) and tumorigenic (MCF7) breast epithelial cells exposed to cigarette smoke acquire mesenchymal properties such as fibroblastoid morphology, increased anchorage-independent growth, and increased motility and invasiveness. Moreover, transplantation experiments in mice demonstrate that treatment with cigarette smoke extract renders MCF 10A cells more capable to survive and colonize the mammary ducts and MCF7 cells more prone to metastasize from a subcutaneous injection site, independent of cigarette smoke effects on the host and stromal environment. The extent of transformation and the resulting phenotype thus appear to be associated with the differentiation state of the cells at the time of exposure. Analysis by flow cytometry showed that treatment with CSE leads to the emergence of a CD44 hi $/ C D 24^{\text {low }}$ population in MCF $10 \mathrm{~A}$ cells and of CD44 ${ }^{+}$and $\mathrm{CD} 49 \mathrm{f}^{+}$MCF7 cells, indicating that cigarette smoke causes the emergence of cell populations bearing markers of self-renewing stem-like cells. The phenotypical alterations induced by cigarette smoke are accompanied by numerous changes in gene expression that are associated with epithelial to mesenchymal transition and tumorigenesis.
\end{abstract}

Conclusions: Our results indicate that exposure to cigarette smoke leads to a more aggressive and transformed phenotype in human mammary epithelial cells and that the differentiation state of the cell at the time of exposure may be an important determinant in the phenotype of the final transformed state.

Keywords: Tobacco, Breast cancer, Cell motility and invasion, Epithelial to mesenchymal transition, Metastasis, Intraductal injection

\footnotetext{
* Correspondence: zahnoci@jhmi.edu

${ }^{1}$ Department of Oncology, The Sidney Kimmel Comprehensive Cancer

Center at Johns Hopkins, Baltimore, MD 21287, USA

Full list of author information is available at the end of the article
} 


\section{Background}

Multiple epidemiological studies have established the association between active and involuntary exposure to tobacco smoke and increased risk of breast cancer. The link, which has been a controversial topic for many years, was initially demonstrated in younger, primarily premenopausal women $[1,2]$, and subsequently in postmenopausal women [2-4]. The epidemiological evidence is backed up by several studies showing that tobacco carcinogens are present and active in the breast tissue of smokers [1,5-7]. Except for the documented formation of mutagenic DNA adducts $[6,8]$, it is unclear how these compounds affect cell behavior in the breast contributing to cancer development, progression, and metastasis. Emerging evidence suggests that cigarette smoke condensate (CSC), or aqueous cigarette smoke extract (CSE) can induce changes in morphology and gene expression indicative of epithelial to mesenchymal transition (EMT) in immortalized human bronchial epithelial cells [9] and in lung carcinoma cells $[9,10]$. This implies the acquisition of mesenchymal properties, including traits that are associated with malignancy such as increased motility and invasiveness [11]. Although these studies provide some mechanistic data on tobacco smoke tumorigenesis in lung, data for breast cancer are limited. In this work we have set out to investigate the progressive transforming effects of tobacco smoke on non-tumorigenic mammary epithelial cells and breast cancer cells using in vitro and in vivo models. Our results indicate that exposure to cigarette smoke leads to a more aggressive and transformed phenotype in human mammary epithelial cells, and that the differentiation state of the cell at the time of exposure may be an important determinant in the phenotype of the final transformed state.

\section{Results \\ Cigarette smoke induces anchorage-independent cell growth, migration, invasion and morphological changes in mammary epithelial cells and breast cancer cells}

It has been shown that the risk of developing cancer increases with the number of years a person has smoked or been exposed to second hand smoke $[12,13]$. For this reason we developed a model to study the progressive, chronic effects of cigarette smoke exposure. Cells were continuously cultured for 72 weeks with an aqueous cigarette smoke extract (CSE) from main stream smoke prepared in our laboratory $(0.25 \%, 0.5 \%$ or $1 \%$ CSE) or for approximately 40 weeks with cigarette smoke condensate (CSC) a commercial product based on condensate from second-hand-like smoke $(10 \mu \mathrm{g} / \mathrm{ml}$ or $25 \mu \mathrm{g} / \mathrm{ml} \mathrm{CSC})$. A concentration of $0.5 \% \mathrm{CSE}$, or $25 \mu \mathrm{g} / \mathrm{ml} \mathrm{CSC}$ in the media corresponds to approximately 0.001 cigarettes $/ \mathrm{ml}$, which is an amount comparable to, or lower than those used in other studies [9,10,14-16]. The corresponding amount of nicotine in the media $(1.3 \pm 0.1 \mu \mathrm{g} / \mathrm{ml})$ approximates the upper limit of the concentrations of cotinine found in the plasma or breast milk of smokers, which has been reported as high as $300-800 \mathrm{ng} / \mathrm{ml}$ and $200-500 \mathrm{ng} / \mathrm{ml}$, respectively [17]. Non-tumorigenic MCF 10A cells cultured with either CSE or CSC were transferred to soft agar to assess anchorage-independent growth after 15, 21, 27 and 39 or 37 weeks of treatment. Both CSE and CSC caused a significant increase in colony formation in soft agar (up to 42 fold; Figure 1A) which is a feature typical of cancer cells. Linear regression analysis indicated that the effect was both dose and time dependent as the number of colonies increased in parallel with the duration of treatment $\left(\mathrm{r}^{2}>0.9 ; P<0.05\right.$ by F-test), and the concentration of CSE or CSC $(P<0.01$ by F-test). The vehicle control for CSC, which contains DMSO, led to the development of slightly more colonies than the saline control for CSE. Treatment with CSE also increased the migratory ability in MCF10As. After treatment with $0.5 \%$ or $1 \%$ CSE for 37 weeks MCF 10A cells showed a 3.1 and 3.6 fold increase in migration, respectively (Figure $1 \mathrm{~B}$ ). The experiment was replicated after 72 weeks of treatment with similar results, suggesting that the initial increase in motility is maintained during prolonged exposure to CSE (Figure 1B). To test whether colony formation and migration were unique to MCF10As or would also occur in other breast cell lines we treated non-tumorigenic, MCF-12A cells with CSC and the breast cancer cell line MCF7 with CSE. For MCF12A, we observed a 4 to 5 -fold increase in colony formation after 18 weeks of treatment (Figure $1 C, P<0.01$ by Student's $t$-test) and a significant increase in migration when exposed to CSC for 18 weeks (Figure 1D). MCF7 cells are capable of forming colonies without CSE treatment; however, a significant increase in colony formation was observed after only nine weeks of treatment with 0.5\% CSE (Figure 1E). Moreover MCF7 cells, which are more motile then MCF $10 \mathrm{~A}$ and $-12 \mathrm{~A}$, and have the ability to migrate through matrigel coated filters, showed a marked increase of their invasive capability when exposed to $0.25 \%$ or $0.5 \%$ CSE for 9 weeks (Figure 1F). All cell lines tested altered their morphology when exposed to CSE or CSC. Untreated MCF 10A and MCF-12A cells normally display a typical cobblestone epithelial morphology in culture. Treatment with CSE or CSC caused them to adopt a more spindle shape and fibroblast-like morphology (shown clearly in the inserts, upper and middle panels, Figure 2), which is consistent with the increased motility that we observed in the migration assays shown in Figure 1. Similarly, MCF7 cells also became more elongated and spindle-shaped after exposure to cigarette smoke (Figure 2, bottom panel). The observed changes in morphology and motility are consistent with phenotypical changes associated with EMT, 

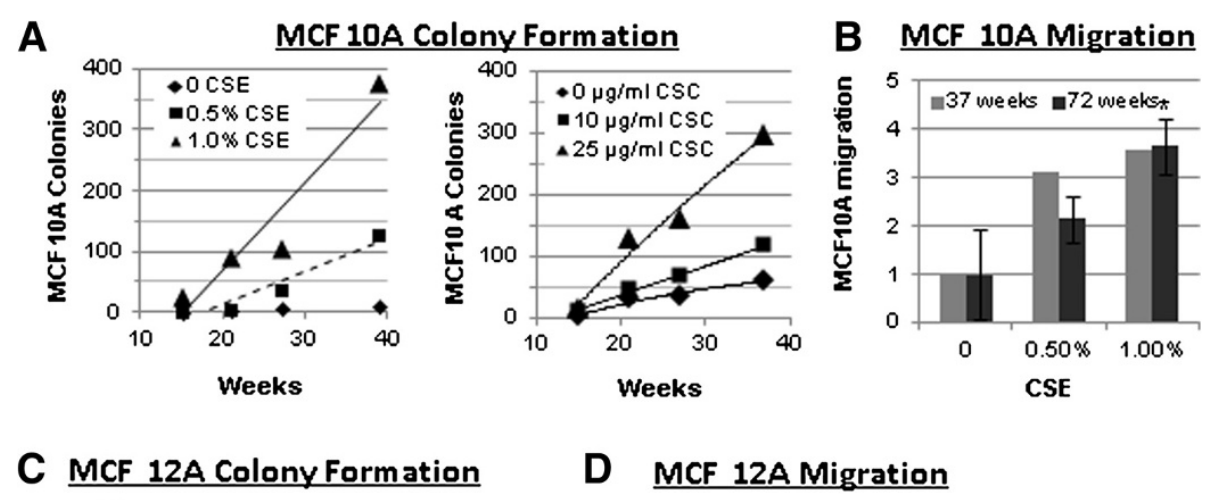

D MCF 12A Migration

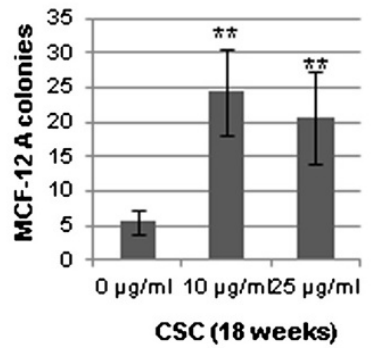

$\mathbf{E}$

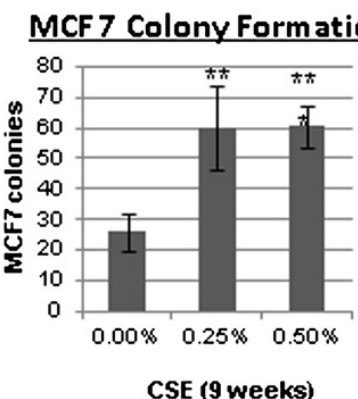

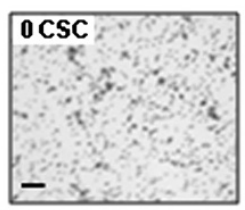
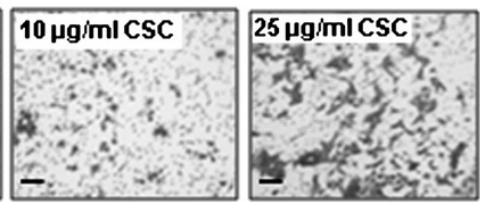

$\mathbf{F}$

MCF 7 Invasion

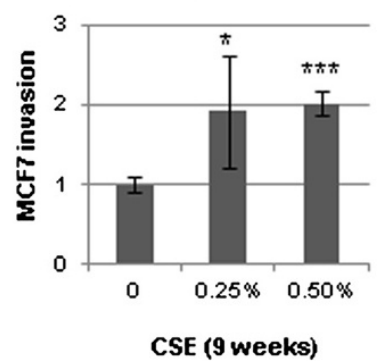

Figure 1 Cigarette smoke induces anchorage-independent cell growth, migration, and invasion in mammary epithelial cell lines. (A) Treatment of MCF10A cells with CSE or CSC leads to soft agar colony formation that increases, as compared to mock, with increased weeks of exposure. (B) Treatment of MCF10A cells with CSE for 37 and 72 weeks leads to increased migration through uncoated transwell inserts as compared to mock treated cells. (E) Treatment of MCF 7 cells with CSE for 9 weeks leads to soft agar colony formation as compared to mock. (F) Treatment of MCF 7 cells with CSE for 9 weeks leads to increased invasion through matrigel-coated transwell inserts as compared to mock. (C) Treatment of MCF12A cells with CSC for 18 weeks leads to increased colony formation as compared to mock. (D) Treatment of MCF12 A cells with CSC leads to increased migration through uncoated transwell inserts as compared to DMSO control The increase in MCF-12A migration (right) was not quantified numerically because the cells became partially confluent after migration and could not be accurately counted. The dark patches are cells stained with crystal violet that have migrated though the filter pores (light grey dots); the size bar represents $100 \mu \mathrm{m}$. Data in bar graphs are mean \pm standard deviation of $3-5$ replicates; ${ }^{*} P<0.05,{ }^{*} P<0.01,{ }^{*}{ }^{*} P<0.001$ by Student's $t$-test.

and suggest that chronic exposure to cigarette smoke may cause breast epithelial cells to acquire mesenchymal properties, which would render them more motile [11]. For cells that are already tumorigenic, such as MCF7, our observations suggest that the phenotype has become more invasive. Similar results were observed using either CSE or CSC, indicating that both mainstream smoke and second hand cigarette smoke contain compounds that can significantly alter the phenotype of these diverse cell lines.
CSE confers the ability to colonize mammary ducts and metastasize to mammary epithelial cells and breast cancer cells, respectively

MCF 10A cells are not able to form tumors in immunodeficient mice, and are thus neither malignant nor tumorigenic. Based on our in vitro results, we hypothesized that treatment with CSE might drive these cells to become more invasive or pre-malignant. To investigate this scenario, we used an intraductal transplantation model originally developed to study ductal carcinoma in 


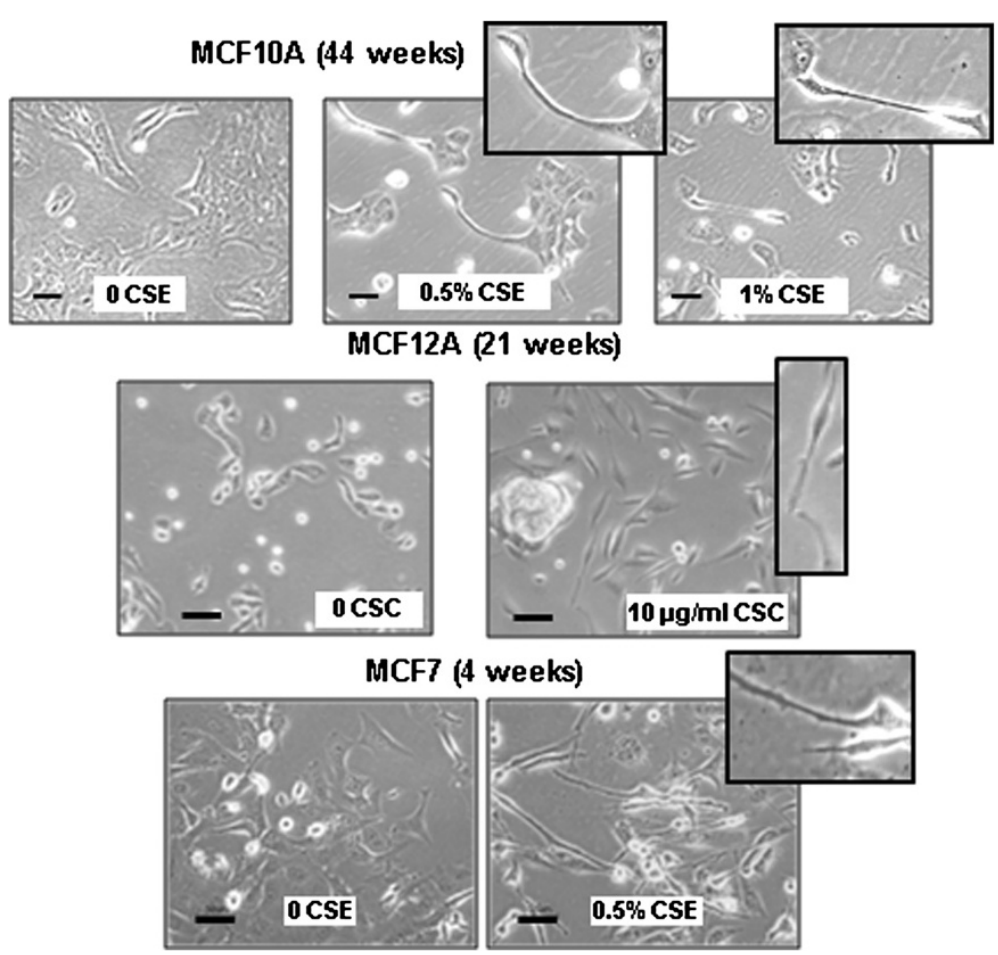

Figure 2 Cigarette smoke induces morphological alterations in mammary epithelial cell lines. Photomicrographs showing morphological alterations of MCF 10A cells exposed to CSE for 44 weeks, MCF-12A cells exposed to CSC for 21 weeks, and MCF7 cells exposed to CSE for 4 weeks. Inserts highlight the spindle shape of cells treated with CSE or CSC. The size bar represents $50 \mu \mathrm{m}$.

situ (DCIS). In this model, cancer cells are injected through the nipple, into the primary mammary duct, which allows in situ analysis of intraductal growth and/or invasion through the basement membrane into the stroma [18]. MCF 10A cells treated with $0.5 \%$ CSE for 46 weeks or mock treated were injected into the primary inguinal mammary ducts of 8-week-old female immunodeficient mice (NSG). The mammary fat pads were harvested after three months and labeled with an antibody for human cytokeratin-18 to identify the injected human cells. Untreated MCF 10A cells did not appear to colonize or grow in the ducts; however, colonies of CSEtreated MCF 10A cells were found within the ducts up to 3 months post-injection (Figure 3A). We then investigated if CSE could further increase the invasiveness of MCF7 breast cancer cells. Because these cells are tumorigenic, and grow much faster than MCF 10A, we harvested the mammary glands seven days after intraductal injection. At that time, untreated MCF7 cells had formed several intraductal masses that appeared to remain within the confines of the ducts. In contrast, MCF7 cells treated with CSE for 21 weeks had invaded through the duct and had formed colonies in the stroma (Figure 3B). Since treatment with CSE had clearly increased the invasiveness of MCF7 cells, we investigated if tumorigenesis and metastasis of MCF7 cells were also affected using a subcutaneous xenograft model. Transplanted MCF7 cells treated with $0.5 \%$ CSE for 18 weeks resulted in smaller tumors than mock-treated cells (Figure 3C); however, these smaller tumors were associated with metastases in the lungs of all animals and isolated cells were found in the liver of at least one animal (Figure 3D). The three mice shown are representative, and two additional mice injected with CSE treated cells were analyzed by gross pathology for a total of 5 . In contrast, we did not observe metastases from untreated MCF7 cells, suggesting that cigarette smoke may have favored the expansion of a highly metastatic subpopulation of MCF7 cells. Although MCF10A cells had exhibited increased intraductal survival and colonization after treatment with CSE, these cells did not produce subcutaneous tumors even after 43 weeks of exposure to CSE.

\section{CSE causes changes in stem cell markers in MCF 10A and MCF7 cells}

Self renewal is a critical component of tumorigenesis [11]. Thus, we analyzed how CSE affects the distribution of specific cell surface markers that are associated with tumor initiation and self renewal, specifically ALDH1 activity, high CD44/low CD24, CD49f and CD133 [19-21]. FACS analysis showed a sharp change in the distribution of CD44 and CD24 in CSE-treated MCF 10A and MCF7 

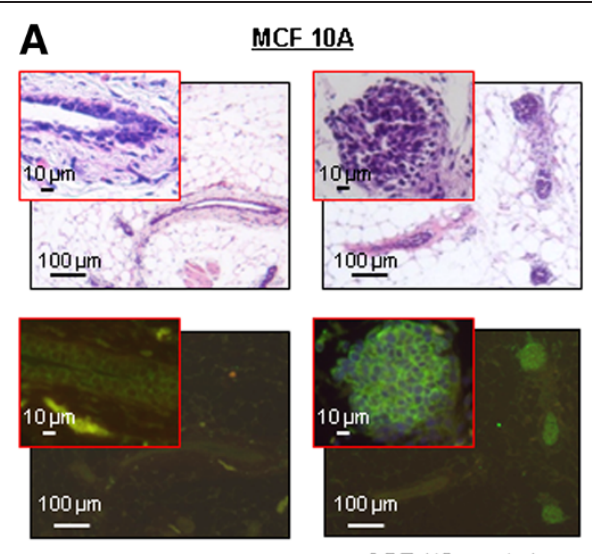

CSE (46 weeks)

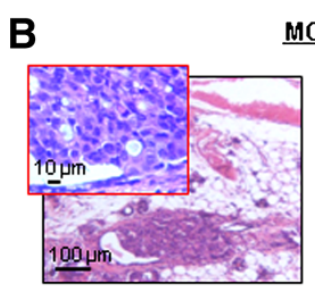

MCF7

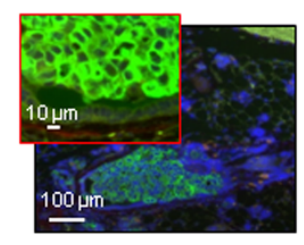

Control
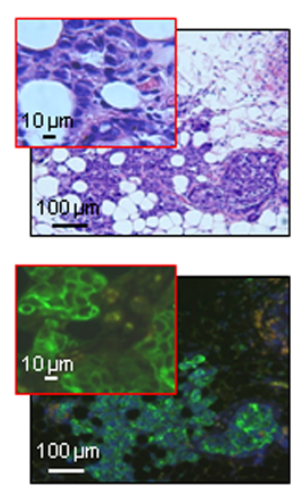

CSE (21 weeks)
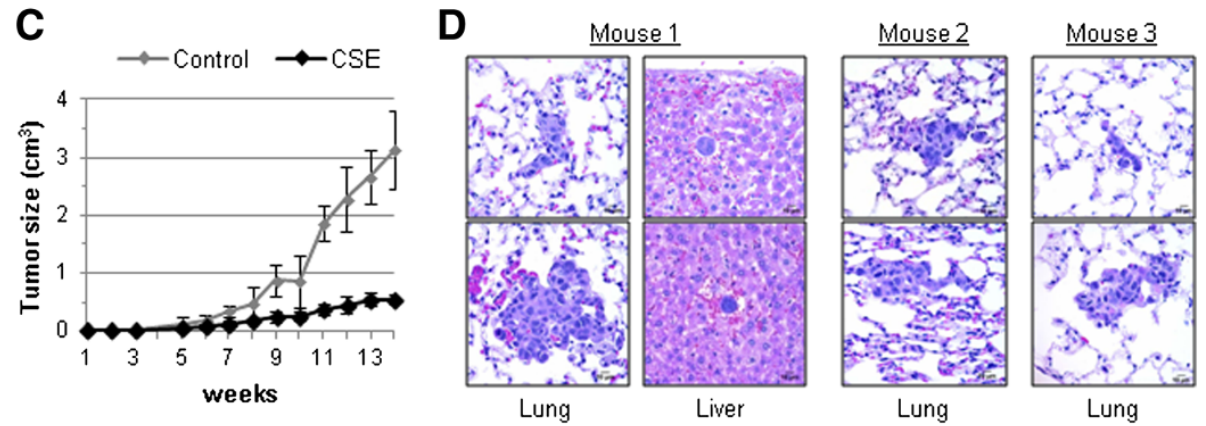

Figure 3 Cigarette smoke facilitates intraductal colonization of MCF 10A cells and distant metastasis of MCF7 cells. (A-B) H\&E and FITC/ DAPI staining of mammary gland sections from NSG immunodeficient mice injected intraductally with 100,000 control or 0.5\% CSE-treated MCF 10A or MCF7 cells. Each mouse was injected at two sites. MCF10 A cells were injected into 3 mice and MCF7 cells into 2 mice for a total of 6 and 4 sites respectively. Two magnifications are shown. The xenografts were analyzed via immunoflourescence using a FITC antibody specific for human cytokeratin-18. (C) Growth of subcutaneous xenograft tumors from control and CSE-treated (0.5\%) MCF7 cells. Each mouse ( $n=5)$ was injected at one site. Mean \pm SD of five replicates are shown. (D) H\&E staining of sections of lung and liver containing metastatic colonies from three representative NSG immunodeficient mice subcutaneously injected with 750,000 MCF7 cells treated with 0.5\% CSE. Two additional mice were analyzed by gross pathology for a total $n=5$.

cells. Most MCF $10 \mathrm{~A}$ cells are CD $44^{+} / \mathrm{CD} 24^{+}$, but after exposure to $0.5 \%$ CSE, at least two cell populations with substantially increased CD44 and lower ALDH activity emerged. In one of these populations the expression of CD24 was particularly low (Figure 4, left panels). In MCF10A cells, the distribution of CD49f was virtually unaffected by treatment with CSE, and the cells appeared uniformly $\mathrm{CD} 4 \mathrm{f}^{+}$(not shown). A small number of $\mathrm{CD}_{133^{+}}$cells that were entirely distinguishable from the CD44hi cells were present in MCF 10A cells treated with 0.5\% CSE, while untreated cells were $\mathrm{CD} 133^{-}$(not shown). MCF7 cells are a mixed population of $\mathrm{CD} 44^{+}$and $\mathrm{CD} 44^{-}$ cells, but are uniformly CD24 $4^{+}$(Figure 4 , right panels). CSE treatment caused a shift to the $\mathrm{CD} 24^{+} / \mathrm{CD} 44^{+}$quadrant, $(76.8 \%$ to $93.1 \%)$ and an increase of CD49f positivity in a portion of the CD44 $4^{+}$cells (18.4\% to $\left.29.9 \%\right)$. These results indicate that chronic low-dose exposure to cigarette smoke can alter cellular distributions of markers associated with self-renewal and stem-like properties.
Exposure of mammary epithelial cells to CSE affects the expression of genes associated with EMT and tumorigenesis

Two clones, designated $\mathrm{SC} 1$ and $\mathrm{SC} 2$ were isolated from MCF 10A cells exposed to 0.5\% CSE for 13 weeks and expanded in the same concentration of CSE for 8 additional weeks, at which time total RNA was isolated for microarray and qPCR analysis. In addition, protein lysates and genomic DNA were prepared from independent samples treated with CSE for 21 weeks. The microarray analysis identified 186 unique genes that were upregulated and 308 unique genes that were downregulated at least two fold in both MCF 10A CSE clones (Additional file 1: Table S1). The expression of selected genes was verified by qRT-PCR or Western blot analysis (Figure 5), focusing on those genes associated with the phenotypes that we had observed, namely EMT, invasion and metastasis. Ecadherin and vimentin, which are associated with an epithelial state [22,23], were downregulated and upregulated 


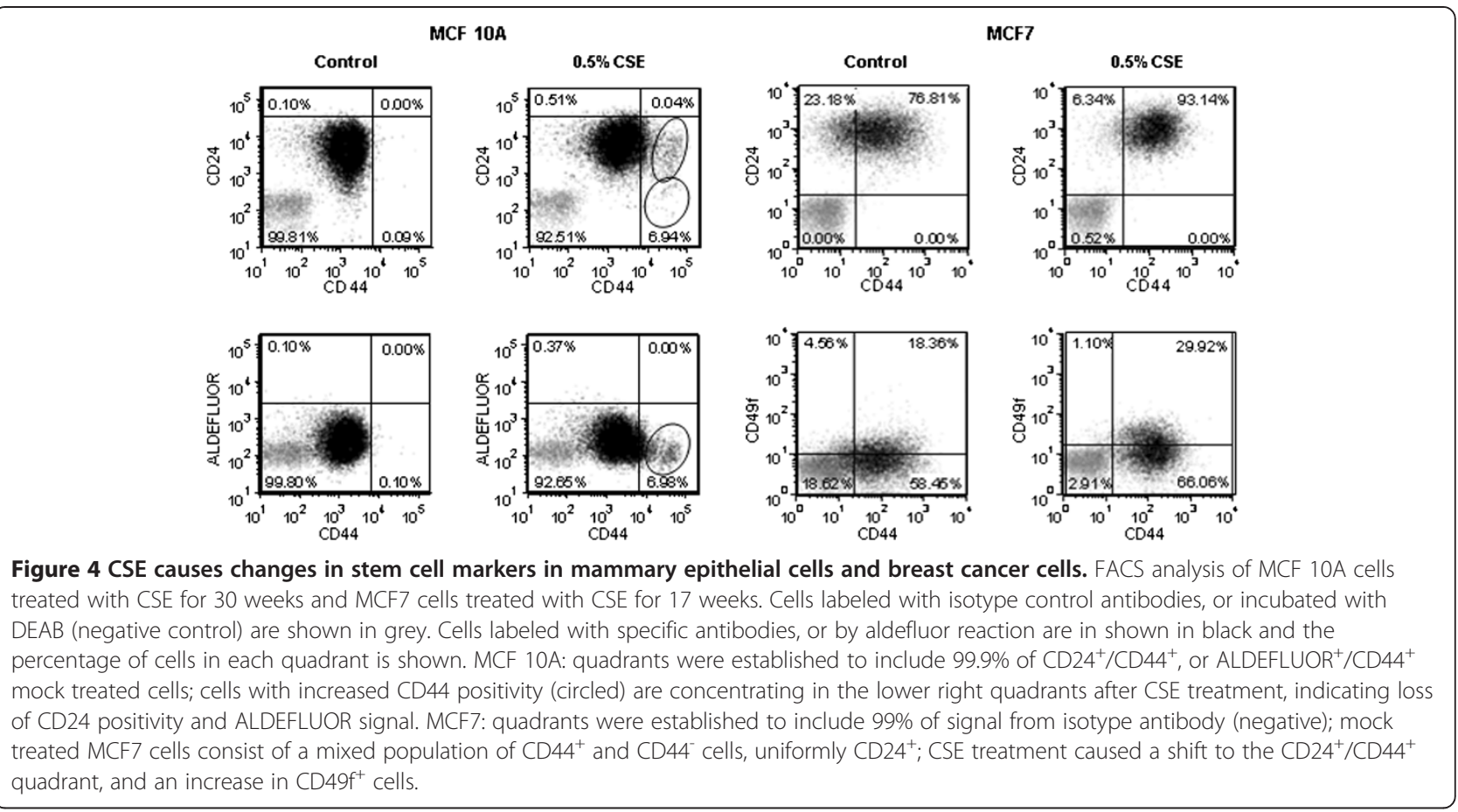

respectively in MCF10As as determined by Western blot analysis (left panel) and PCR (right panel) at 21 weeks (Figure 5A). Similar changes were observed by Western blot analysis for MCF7 cells; however, vimentin data is only shown for a $0.25 \%$ CSE treatment (Figure 5A, left panel). Decreases in occludin, and increases in $\mathrm{N}$-cadherin and fibronectin, which are also associated with a mesenchymal state [22], were observed in MCF10A cells treated with CSE for 21 weeks (Figure 5B left panel). In addition, we observed dysregulation of occludin and $\mathrm{N}$-cadherin in an independent RNA sample of MCF 10A cells treated with CSE for 40 weeks (Figure 5B, right panel). We also observed a general downregulation of keratins (Additional file 1: Table S1), which is another hallmark of EMT [22]. Several members of the claudin family of tight-junction proteins were downregulated (Figure $5 \mathrm{C}$ ), which fits with the observed increased motility induced by CSE treatment. The EMT-promoting transcription factors TWIST1, TWIST2, ZEB1, ZEB2, and FOXC2 were upregulated, while FOXC1 and SNAI1 (Snail) were downregulated by CSE in MCF 10A cells (Figure 5D). These transcription factors can be induced through TGF- $\beta$ signaling $[24,25]$, and we observed that TGF- $\beta$ receptor I and III (TGFBR1, TGFBR3), and TGF- $\beta 2$ (TGFB2) were upregulated in MCF 10A cells treated with CSE (Figure 5E). Some of these gene expression changes were significant in only one of the two CSE-treated MCF 10A clones indicating variability in the response to smoke exposure. Upregulation of TWIST1 and TWIST2, as well as of TGFBR3 was also observed in MCF 10A treated with CSE for 40 weeks, together with TGFB1, but not TGFB2 (Figure 5F). Since exposure to cigarette smoke has been previously linked to epigenetic silencing in human cancer [26,27], we investigated if promoter methylation could be responsible for gene downregulation in our model. We used a DNA methylation array to estimate the proportion of methylated loci (beta-value) in MCF 10A cells treated with CSE for 21 weeks (Additional file 2: Table S2), focusing on sites located within promoter $\mathrm{CpG}$ islands. The beta value of one occludin probe increased from 0.11 to 0.50 after treatment with CSE, indicating a substantial increase in methylation. Similarly, the beta-value of one claudin 1 site increased from 0.06 to 0.55 . None of the other downregulated genes that we had validated up to this point were affected according to this analysis. However, we observed increased methylation of estrogen receptor beta (ER $\beta ; 0.17$ to 0.72 ), which can act as a tumor suppressor in the mammary epithelium [28]. Western blot analysis showed that the expression of ER $\beta$ was reduced in MCF 10A and MCF7 cells treated with CSE (Figure 6). Although our data are in agreement with other published reports and suggest that this receptor may be epigenetically repressed by cigarette smoke, we cannot discount alternative transcriptional mechanisms and processes related to protein degradation or decreased stability.

\section{Discussion}

After many years of debate, there is now ample proof that tobacco smoke increases the risk of breast cancer. Multiple studies, including some published after the last 

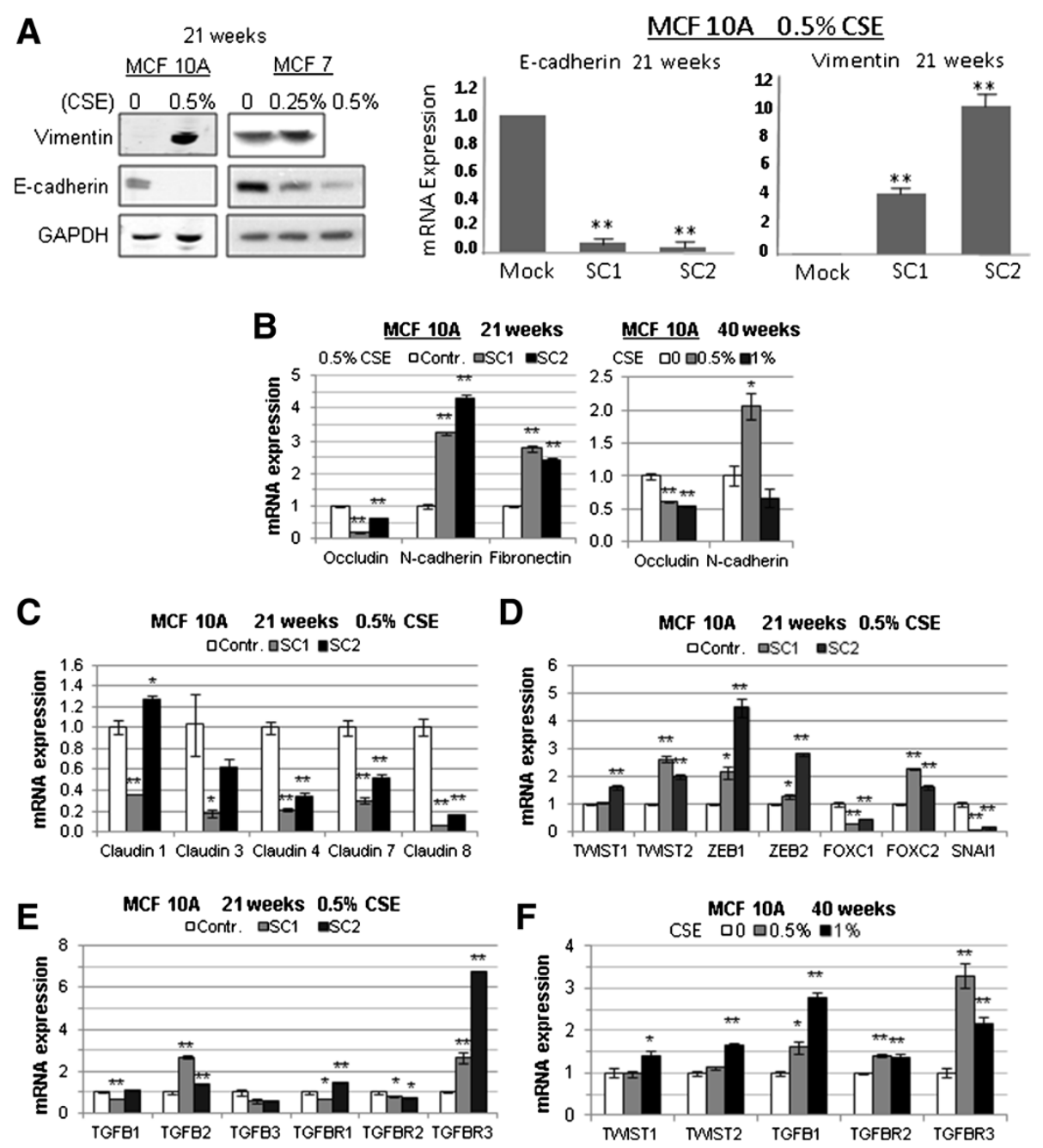

Figure 5 Exposure of mammary epithelial cells to CSE leads to gene expression changes indicative of EMT. (A, left panel) Western Blot showing upregulation of Vimentin and downregulation of E-cadherin in MCF10A and MCF7 cells exposed to CSE for 21 weeks. (A, right panel) qRT PCR analysis showing downregulation of e-cadherin mRNA and upregulation of Vimentin mRNA in two MCF10A subclones after 21 weeks of exposure to $0.5 \%$ CSE. (B) qRT PCR analysis showing downregulation of occludin and upregulation of N-cadherin and fibronectin in two MCF10A subclones at 21 and 40 weeks of exposure. (C-F) qRT PCR analysis of EMT genes in MCF 10A mammary epithelial cells exposed to $0.5 \%$ CSE for 21 weeks (clones SC1 and SC2) or 0.5-1.0\% CSE for 40 weeks (without subcloning). Data in bar graphs are mean \pm standard deviation of 3 replicates; ${ }^{*} P<0.01,{ }^{* *} P<0.001$.

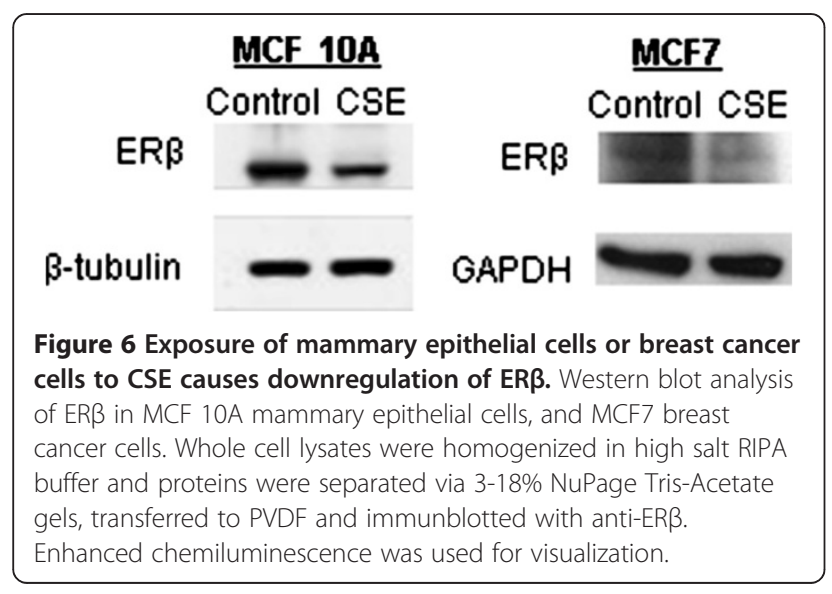

Surgeon General Report [5] and IARC monographs on the subject [29] show that active and passive exposure to tobacco smoke increases the risk of breast cancer in both premenopausal and postmenopausal women [1-5]. With the epidemiological evidence now conclusive, the task remains to investigate the molecular mechanism by which exposure to tobacco smoke, either voluntary or involuntary, leads to increased breast cancer risk [5].

The response of breast epithelial cells and breast cancer cell to cigarette smoke has been previously examined $[15,16,30,31]$, but these studies focused on short-term treatment (up to one week) while we have analyzed the effect of continuous long-term exposure. We demonstrated that chronic exposure to tobacco smoke in the form of 
CSE or CSC can alter the phenotype of mammary epithelial cells, promoting the acquisition of mesenchymal traits such as increased anchorage-independent growth, motility, invasion, and the expression of markers associated with self-renewal and tumor initiation. Numerous groups have demonstrated the emergence of a CD $44^{+} / \mathrm{CD} 24^{-/ \text {low }}$ stem-like signature from $\mathrm{CD} 44^{+/ \mathrm{low}} / \mathrm{CD} 24^{+}$cells upon the induction of an EMT phenotype characterized by loss of E-cadherin and gain of vimentin [11,32]. The $\mathrm{CD} 44^{+} / \mathrm{CD} 24^{-/ \text {low }}$ phenotype has been consistently associated with self-renewing mammary epithelial cells, which are also more tumorigenic and basal-like than CD $44^{+} / \mathrm{CD} 24^{+}$cells [33]. Similarly, we showed that treatment of MCF 10A cells with CSE leads to the emergence of a $\mathrm{CD} 44^{\mathrm{hi}} / \mathrm{CD} 24^{\text {low }}$ population, and our in vivo experiments demonstrated that CSE-treated MCF 10A cells have increased survival and colonization ability. Although MCF 10A cells did not become malignant, treatment of the MCF7 cancer cell line led to increased metastatic potential, consistent with published evidence that the differentiation state of the cell of origin is a strong determinant of the cellular phenotype of the final transformed state [34]. Other studies in animal models have previously shown that tobacco smoke can increase the risk of metastasis from breast cancer, but this has been attributed mainly to smoking-induced inhibition of host antitumor immune defenses, or to damage of the host tissue $[35,36]$. In contrast, our data from ex vivo exposure followed by orthotopic or subcutaneous transplantation into mice indicate that tobacco smoke can directly affect the ability of breast epithelial cells to invade or metastasize, independent of other cigarette smoke effects on the host and stromal environment.

The phenotypical alterations induced by cigarette smoke were accompanied by multiple gene expression changes. We concentrated our analysis on genes associated with EMT, loss of tumor suppression and the acquisition of malignancy traits. Our data indicates that ER $\beta$ is epigenetically repressed by tobacco smoke, which is consistent with a recent study showing that methylation of ER $\beta$ is a frequent event in breast cancer [37]. Contrary to the better known and structurally similar ER $\alpha$, ER $\beta$ does not induce mitogenic response and can reduce basal, hormone-independent cell proliferation [28]. ER $\beta$ is widely expressed in normal mammary epithelium, but frequently lost in breast cancer, where its presence generally correlates with better prognosis [28,38]. Knock down of ER $\beta$ in MCF 10A or MCF7 cells was shown to cause a significant growth increase of both cell types in a ligand-independent manner [38], while expression of exogenous $E R \beta$ in the receptor negative breast cancer cell line MDA-MB-231 inhibited proliferation [39]. Cigarette smoke also caused downregulation of claudin 1, 3, 4, 7, and 8 . The claudins are integral components of tight junctions, and their expression in cancer appears to be tissue specific, with some claudins downregulated in certain tumors and upregulated in others [40]. A small subgroup of breast cancer has been identified as expressing low levels of claudins, and is referred to as the "claudin low" group [41-43]. Claudin low tumors represent $12-13 \%$ of breast cancers, are generally basal like, and overexpress EMT markers [41-43]. Mouse claudin-low tumors generated in a p53-null animal model were found to be markedly enriched in tumor-initiating cells [44]. Consistently, our claudin-low CSE-treated breast cells are more tumorigenic than untreated cells, and exhibit gene expression changes indicative of EMT, such as downregulation of Ecadherin and occludin, and upregulation of N-cadherin, fibronectin and vimentin. Downregulation of occludin can reduce cancer sensitivity to apoptogenic factors by modulating apoptosis-associated genes. In addition, occludin decreases cellular invasiveness and motility, thus its downregulation can potentially favor cancer metastasis [45]. The downregulation of occludin and claudin 1 [46] may also be the result of epigenetic regulation, since we have observed increased methylation at the promoter of these genes and in the case of claudin 1, the gene can be re-expressed with demethylating agents such as 5azacytidine and decitabine [46]. CSE treatment upregulated TGFBR3 and TGFB2 in MCF 10A cells, which is consistent with the reported observation that endothelial cells undergoing EMT express TGFBR3, and TGFBR3-specific antisera can inhibit mesenchyme formation and migration [24]. Moreover, ectopic overexpression of TGFBR3 in nontransforming ventricular endothelial cells conferred transformation in response to TGFB2 [24]. Since we observed upregulation of TGFBR3 and TGFB2 in MCF 10A cells that are undergoing EMT-like changes, but are not completely transformed by cigarette smoke, our results suggest that overexpression of these two genes by cigarette smoke may be a component of EMT that is not associated with transformation. Alternatively, this could be a very early event in transformation and cancer development. We also observed that the EMT-promoting transcription factors TWIST1, TWIST2, ZEB1, ZEB2 and FOXC2 were upregulated, while FOXC1 and SNAI1 (Snail) were downregulated by CSE. Except for the decreased SNAI1, these data are consistent with recent reports that the MDA-MB -231 and MDA-MB-435 basal B cell lines express higher levels of fibronectin, $\mathrm{N}$-cadherin, SNAI1 and ZEB2, and lower E-cadherin and FOXC1 than the luminal epithelial cell line, MCF7 [25]. The same study showed that overexpression of TWIST1, as well as the EMT-promoting factor TGF- $\beta 1$, consistently upregulates $Z E B 1$ and $Z E B 2$ and $F O X C 2$ in human mammary epithelial cells. Interestingly, TGF- $\beta 1$ is up-regulated by TWIST1, but is not required for TWIST1-induced up-regulation of FOXC2, which occurs in mammary epithelial cells overexpressing 
TWIST1 even in the presence of a TGF- $\beta$ signaling inhibitor [25]. Taken together our observations in the MCF 10A breast epithelial cell line exposed to CSE are consistent with a model of EMT where TWIST drives the transition and upregulates $F O X C 2, Z E B 1$ and $Z E B 2$, with potential involvement of TGF $\beta$ signaling.

\section{Conclusions}

Our results indicate that chronic, long-term exposure to cigarette smoke leads to a more aggressive and transformed phenotype in human mammary epithelial cells, and that the differentiation state of the cell at the time of exposure may be a critical determinant in the phenotype of the final transformed state. Non-malignant, human mammary epithelial cells (MCF 10A) exposed to cigarette smoke in the form of CSE survived intraductally in a mouse mammary gland many months beyond their normal capacity, and breast cancer cells which normally do not metastasize in mice (MCF7), formed metastatic colonies in the lung. All CSE-treated cell lines showed EMT-like behavior including increased anchorage-independent growth, increased motility and invasiveness, and we observed an increase in markers of self-renewing cells, along with accompanying gene expression changes indicative of EMT and malignancy.

\section{Methods}

\section{Cell culture model of exposure to cigarette smoke}

Cigarette smoke extract (CSE) was prepared weekly by burning 2 complete 1R3F cigarettes (Kentucky Tobacco Research and Development Center, Lexington, KY, USA) and drawing the smoke by vacuum into $10 \mathrm{ml}$ of sterile PBS. CSE concentration was evaluated by measuring the optical density at $502.4 \mathrm{~nm}$, and diluted to $\mathrm{O}$. D. $=0.10 \pm 0.01$ [47]. This solution was considered $100 \%$ CSE. The concentration of nicotine was evaluated by mass spectrometry as previously described [48]. The $100 \%$ CSE contained $253 \pm 22 \mu \mathrm{g} / \mathrm{ml}$ of nicotine which is equivalent to 0.2 cigarettes $/ \mathrm{ml}$. Cigarette smoke condensate (CSC) was purchased from Murty pharmaceuticals (Lexington, KY, USA) and is prepared by smoking a 1R3F cigarette on a smoking machine and collecting the particulate matter from the side stream smoke onto a filter for extraction with DMSO. Cell lines were purchased from ATCC (Manassas, VA, USA) and cultured with either CSE, or CSC refreshing the media and additives twice a week (see Additional file 3 for media formulation).

\section{In vitro transformation assays}

Anchorage-independent growth was assessed by seeding the cells on soft agar ( $0.4 \%$ top layer, $0.8 \%$ bottom layer); and counting the colonies after 14 days using an inverted microscope and $0.005 \%$ crystal violet for staining. Cell migration and invasion was assessed in Boyden chambers using $8 \mu \mathrm{m}$-pore inserts, with or without matrigel coating (BD Bioscience, San Jose, CA, USA) according to the manufacturer's instructions.

\section{Animal studies}

NOD-SCID and NSG mice were purchased from The Jackson Laboratory (Bar Harbor, ME, USA), and cared for in strict accordance with an approved Johns Hopkins ACUC protocol. Intraductal transplantation was performed as described previously [18]. Briefly, $10^{5}$ cells were injected in the mammary ducts of immunodeficient female NSG mice as $2 \mu \mathrm{L}$ of single-cell suspension in PBS with $0.1 \%$ trypan blue, using a Hamilton syringe with a blunt-ended 1/2-inch 30-gauge needle. At the indicated times, mice were euthanized, and the mammary fat pads harvested and fixed in $10 \%$ neutral buffer formalin. For xenografts, CSE treated cells $\left(10^{6}\right)$ were subcutaneously injected as a $50 \mu \mathrm{l}$ single-cell suspension in a 1:1 solution of media and BD Matrigel Matrix (BD Bioscience). At the indicated times, the mice were euthanized, and fixed by perfusion with PBS followed by $10 \%$ neutral buffer formalin for necropsy. Female mice receiving MCF7 cells were implanted with beeswax pellets containing $20 \mu \mathrm{g}$ of estrogen one day before injection [49]. Paraffin embedded sections were analyzed by standard $\mathrm{H} \& \mathrm{E}$ staining, and by immunohistochemistry using a monoclonal antibody for human cytokeratin-18 (C1399, Sigma-Aldrich, St. Louis, MO, USA), and the Mouse on Mouse (M.O.M.) Fluorescein Kit (Vector Labs, Burlingame, CA, USA).

\section{Flow cytometry}

Fluorescence-activated cell sorting (FACS) was performed on a BD Bioscience SLRII instrument. Cells were labeled using the ALDEFLUOR ${ }^{\star}$ kit (Stem Cell Technologies, Vancouver, BC, Canada), or the antibody conjugates listed in the Additional file 3.

\section{Analysis of gene expression and methylation}

Microarray based gene expression and methylation analysis were performed at the microarray core of the SKCCC using the Agilent Human 44K expression array (Agilent Technologies, Santa Clara, CA, USA) and the Infinium Methylation27 Array (Illumina, Inc., San Diego, CA, USA) as previously described [50]. The data is deposited in the GEO database under accession number GSE42668. Quantitative Real-Time PCR analysis (qRTPCR) was performed using a 7500 Real-Time PCR System, the High Capacity cDNA Reverse Transcription Kit, TaqMan Gene Expression Master Mix, and the TaqMan Gene Expression Assays listed in the Additional file 3 (Applied Biosystems, Foster City, CA, US). Western blot analysis was performed as previously described [50] using the antibodies listed in the Additional file 3. 


\section{Additional files}

Additional file 1: Table S1. Summary of the results of the gene expression microarray analysis. Probes showing a difference in gene expression of 2-folds or more in at least one clone are shown. The complete data is available in the GEO database under accession number GSE42668.

Additional file 2: Table S2. Summary of the results of the gene methylation microarray analysis. Probes showing an increase in betavalue of 0.2 or more in CSE-treated MCF10A cells are shown. The complete data is available in the GEO database under accession number GSE42668.

Additional file 3. Cell culture media, TaqMan Gene Expression Assays, and antibodies (western blot and flow cytometry) used in this study.

\section{Competing interests}

The authors declare that they have no competing interests.

\section{Authors' contributions}

FDC and VLF participated in the design and execution of the overall study. VLF, HL, and BVP carried out in vitro experiments. BG, KH, JS, and RB carried out in vivo mouse experiments. WW analyzed the microarray data. CB carried out the pathologic analysis. SBB and CAZ conceived the study and interpreted the results. FDC and CAZ wrote the paper and all authors read and approved the final manuscript.

\section{Acknowledgements}

This work was supported by the Flight Attendant Medical Research Institute [062544_YCSA, 072156_CIA]; the Safeway Foundation; the Irving Hansen Foundation; and the National Institutes of Health [P30 CA006973].

\section{Author details}

'Department of Oncology, The Sidney Kimmel Comprehensive Cance Center at Johns Hopkins, Baltimore, MD 21287, USA. ${ }^{2}$ Department of Molecular and Comparative Pathobiology, The Johns Hopkins University School of Medicine, Baltimore, MD 21205, USA

Received: 8 March 2013 Accepted: 25 July 2013

Published: 6 August 2013

\section{References}

1. Miller MD, Marty MA, Broadwin R, Johnson KC, Salmon AG, Winder B, Steinmaus C, California Environmental Protection Agency: The association between exposure to environmental tobacco smoke and breast cancer: a review by the California environmental protection agency. Prev Med 2007, 44(2):93-106.

2. Johnson KC, Miller AB, Collishaw NE, Palmer JR, Hammond SK, Salmon AG, Cantor KP, Miller MD, Boyd NF, Millar J, Turcotte F: Active smoking and secondhand smoke increase breast cancer risk: the report of the Canadian expert panel on tobacco smoke and breast cancer risk (2009). Tob Control 2011, 20(1):e2.

3. Reynolds P, Goldberg D, Hurley S, Nelson DO, Largent J, Henderson KD, Bernstein L: Passive smoking and risk of breast cancer in the California teachers study. Cancer Epidemiol Biomarkers Prev 2009, 18(12):3389-3398.

4. Luo J, Margolis KL, Wactawski-Wende J, Horn K, Messina C, Stefanick ML, Tindle HA, Tong E, Rohan TE: Association of active and passive smoking with risk of breast cancer among postmenopausal women: a prospective cohort study. BMJ 2011, 342:d1016.

5. United States. Public Health Service. Office of the Surgeon General, United States. Office on Smoking and Health: How tobacco smoke causes disease: the biology and behavioral basis for smoking-attributable disease: a report of the Surgeon General. Rockville, MD; Washington, DC: U.S. Dept. of Health and Human Services, Public Health Service, Office of Surgeon General; for sale by the Supt. of Documents, U.S. G.P.O; 2010.

6. Faraglia B, Chen SY, Gammon MD, Zhang Y, Teitelbaum SL, Neugut Al, Ahsan H, Garbowski GC, Hibshoosh H, Lin D, Kadlubar FF, Santella RM: Evaluation of 4-aminobiphenyl-DNA adducts in human breast cancer: the influence of tobacco smoke. Carcinogenesis 2003, 24(4):719-725.
7. Williams JA, Phillips DH: Mammary expression of xenobiotic metabolizing enzymes and their potential role in breast cancer. Cancer Res 2000, 60(17):4667-4677.

8. Firozi PF, Bondy ML, Sahin AA, Chang P, Lukmanji F, Singletary ES, Hassan MM, Li D: Aromatic DNA adducts and polymorphisms of CYP1A1, NAT2, and GSTM1 in breast cancer. Carcinogenesis 2002, 23(2):301-306.

9. Veljkovic E, Jiricny J, Menigatti M, Rehrauer H, Han W: Chronic exposure to cigarette smoke condensate in vitro induces epithelial to mesenchymal transition-like changes in human bronchial epithelial cells, BEAS-2B. Toxicol In Vitro 2011, 25(2):446-453.

10. Zhang H, Liu H, Borok Z, Davies KJ, Ursini F, Forman HJ: Cigarette smoke extract stimulates epithelial-mesenchymal transition through Src activation. Free Radic Biol Med 2012, 52(8):1437-1442.

11. Mani SA, Guo W, Liao MJ, Eaton EN, Ayyanan A, Zhou AY, Brooks M, Reinhard F, Zhang CC, Shipitsin M, Campbell LL, Polyak K, Brisken C, Yang J, Weinberg RA: The epithelial-mesenchymal transition generates cells with properties of stem cells. Cell 2008, 133(4):704-715.

12. Thun MJ, Myers DG, Day-Lally C, Namboodiri MM, Calle EE, Flanders WD, Adams SL, Heath CW Jr: Age and the exposure-response relationships between cigarette smoking and premature death in cancer prevention study II. In Changes in cigarette-related disease risks and their implications for prevention and control. Edited by Shopland DR. Bethesda, Maryland: National Institutes of Health; 1997:383-413.

13. Jha $P$, Ramasundarahettige $C$, Landsman V, Rostron B, Thun M, Anderson RN, McAfee T, Peto R: 21st-century hazards of smoking and benefits of cessation in the United States. N Engl J Med 2013, 368(4):341-350.

14. Liu F, Killian JK, Yang M, Walker RL, Hong JA, Zhang M, Davis S, Zhang Y, Hussain M, Xi S, Rao M, Meltzer PA, Schrump DS: Epigenomic alterations and gene expression profiles in respiratory epithelia exposed to cigarette smoke condensate. Oncogene 2010, 29(25):3650-3664.

15. Narayan S, Jaiswal AS, Kang D, Srivastava P, Das GM, Gairola CG: Cigarette smoke condensate-induced transformation of normal human breast epithelial cells in vitro. Oncogene 2004, 23(35):5880-5889.

16. Connors SK, Balusu R, Kundu CN, Jaiswal AS, Gairola CG, Narayan S: $\mathrm{C} / \mathrm{EBPb}$ ta-mediated transcriptional regulation of bcl-xl gene expression in human breast epithelial cells in response to cigarette smoke condensate. Oncogene 2009, 28(6):921-932.

17. Luck W, Nau H: Nicotine and cotinine concentrations in serum and milk of nursing smokers. Br J Clin Pharmacol 1984, 18(1):9-15.

18. Behbod F, Kittrell FS, LaMarca H, Edwards D, Kerbawy S, Heestand JC, Young E, Mukhopadhyay P, Yeh HW, Allred DC, Hu M, Polyak K, Rosen JM, Medina D: An intraductal human-in-mouse transplantation model mimics the subtypes of ductal carcinoma in situ. Breast Cancer Res 2009, 11(5):R66

19. Fillmore CM, Kuperwasser C: Human breast cancer cell lines contain stemlike cells that self-renew, give rise to phenotypically diverse progeny and survive chemotherapy. Breast Cancer Res 2008, 10(2):R25.

20. Meyer MJ, Fleming JM, Lin AF, Hussnain SA, Ginsburg E, Vonderhaar BK: CD44posCD49fhiCD133/2hi defines xenograft-initiating cells in estrogen receptor-negative breast cancer. Cancer Res 2010, 70(11):4624-4633.

21. Ginestier $\mathrm{C}$, Hur MH, Charafe-Jauffret E, Monville F, Dutcher J, Brown M, Jacquemier J, Viens P, Kleer CG, Liu S, Schott A, Hayes D, Birnbaum D, Wicha MS, Dontu G: ALDH1 is a marker of normal and malignant human mammary stem cells and a predictor of poor clinical outcome. Cell Stem Cell 2007, 1(5):555-567.

22. Lee JM, Dedhar S, Kalluri R, Thompson EW: The epithelial-mesenchymal transition: new insights in signaling, development, and disease. $J$ Cell Biol 2006, 172(7):973-981.

23. Vuoriluoto K, Haugen H, Kiviluoto S, Mpindi JP, Nevo J, Gjerdrum C, Tiron C, Lorens JB, Ivaska J: Vimentin regulates EMT induction by Slug and oncogenic $\mathrm{H}$-Ras and migration by governing $\mathrm{Axl}$ expression in breast cancer. Oncogene 2011, 30(12):1436-1448.

24. Brown CB, Boyer AS, Runyan RB, Barnett JV: Requirement of type III TGFbeta receptor for endocardial cell transformation in the heart. Science 1999, 283(5410):2080-2082.

25. Taube JH, Herschkowitz J, Komurov K, Zhou AY, Gupta S, Yang J, Hartwell K, Onder T, Gupta PB, Evans KW, Hollier BG, Ram PT, Lander ES, Rosen JM, Weinberg RA, Mani SA: Core epithelial-to-mesenchymal transition interactome gene-expression signature is associated with claudin-low and metaplastic breast cancer subtypes. Proc Natl Acad Sci USA 2010, 107(35):15449-15454. 
26. Wilhelm-Benartzi CS, Christensen BC, Koestler DC, Andres Houseman E, Schned AR, Karagas MR, Kelsey KT, Marsit CJ: Association of secondhand smoke exposures with DNA methylation in bladder carcinomas. Cancer Causes Control 2011, 22(8):1205-1213.

27. Ma YT, Collins SI, Young LS, Murray PG, Woodman CB: Smoking initiation is followed by the early acquisition of epigenetic change in cervical epithelium: a longitudinal study. Br J Cancer 2011, 104(9):1500-1504.

28. Grober OM, Mutarelli M, Giurato G, Ravo M, Cicatiello L, De Filippo MR, Ferraro L, Nassa G, Papa MF, Paris O, Tarallo R, Luo S, Schroth GP, Benes V, Weisz A: Global analysis of estrogen receptor beta binding to breast cancer cell genome reveals an extensive interplay with estrogen receptor alpha for target gene regulation. BMC Genomics 2011, 12:36.

29. IARC Working Group on the Evaluation of Carcinogenic Risks to Humans: Tobacco smoke and involuntary smoking. IARC Monogr Eval Carcinog Risks Hum 2004, 83:1-1438.

30. Martin MB, Reiter R, Johnson M, Shah MS, lann MC, Singh B, Richards JK, Wang A, Stoica A: Effects of tobacco smoke condensate on estrogen receptor-alpha gene expression and activity. Endocrinology 2007, 148(10):4676-4686.

31. Botlagunta M, Winnard PT Jr, Raman V: Neoplastic transformation of breast epithelial cells by genotoxic stress. BMC Cancer 2010, 10. 343-2407-10-343.

32. Morel AP, Lievre M, Thomas C, Hinkal G, Ansieau S, Puisieux A: Generation of breast cancer stem cells through epithelial-mesenchymal transition. PLoS One 2008, 3(8):e2888.

33. Al-Hajj M, Wicha MS, Benito-Hernandez A, Morrison SJ, Clarke MF: Prospective identification of tumorigenic breast cancer cells. Proc Natl Acad Sci USA 2003, 100(7):3983-3988.

34. Ince TA, Richardson AL, Bell GW, Saitoh M, Godar S, Karnoub AE, Iglehart JD, Weinberg RA: Transformation of different human breast epithelial cell types leads to distinct tumor phenotypes. Cancer Cell 2007, 12(2):160-170.

35. Murin S, Inciardi J: Cigarette smoking and the risk of pulmonary metastasis from breast cancer. Chest 2001, 119(6):1635-1640.

36. Murin S, Pinkerton KE, Hubbard NE, Erickson K: The effect of cigarette smoke exposure on pulmonary metastatic disease in a murine model of metastatic breast cancer. Chest 2004, 125(4):1467-1471.

37. Zhao L, Yu Z, Li Y, Wen X, Ma W, Wang L, Ren J, Liu C, He M, Bai X, Sun M, Zheng Z, Mi X, Wang E, Olopade OI, Jin F, Wei M: Clinical implications of ERbeta methylation on sporadic breast cancers in Chinese women. Med Oncol 2012, 29(3):1569-1575.

38. Treeck $\mathrm{O}$, Lattrich $\mathrm{C}$, Springwald A, Ortmann O: Estrogen receptor beta exerts growth-inhibitory effects on human mammary epithelial cells. Breast Cancer Res Treat 2010, 120(3):557-565.

39. Lazennec G, Bresson D, Lucas A, Chauveau C, Vignon F: ER beta inhibits proliferation and invasion of breast cancer cells. Endocrinology 2001, 142(9):4120-4130.

40. Singh $A B$, Sharma $A$, Dhawan $P$ : Claudin family of proteins and cancer: an overview. J Oncol 2010, 2010:541957.

41. Herschkowitz JI, Simin K, Weigman VJ, Mikaelian I, Usary J, Hu Z, Rasmussen KE, Jones LP, Assefnia S, Chandrasekharan S, Backlund MG, Yin Y, Khramtsov Al, Bastein R, Quackenbush J, Glazer Rl, Brown PH, Green JE, Kopelovich L, Furth PA, Palazzo JP, Olopade OI, Bernard PS, Churchill GA, Van Dyke T, Perou CM: Identification of conserved gene expression features between murine mammary carcinoma models and human breast tumors. Genome Biol 2007, 8(5):R76.

42. Prat A, Parker JS, Karginova O, Fan C, Livasy C, Herschkowitz Jl, He X, Perou CM: Phenotypic and molecular characterization of the claudin-low intrinsic subtype of breast cancer. Breast Cancer Res 2010, 12(5):R68.

43. Lu S, Singh K, Mangray S, Tavares R, Noble L, Resnick MB, Yakirevich E: Claudin expression in high-grade invasive ductal carcinoma of the breast: correlation with the molecular subtype. Mod Pathol 2012. Epub ahead of print.

44. Herschkowitz JI, Zhao W, Zhang M, Usary J, Murrow G, Edwards D, Knezevic J, Greene SB, Darr D, Troester MA, Hilsenbeck SG, Medina D, Perou CM, Rosen JM: Comparative oncogenomics identifies breast tumors enriched in functional tumor-initiating cells. Proc Natl Acad Sci USA 2012, 109(8):2778-2783.

45. Osanai M, Murata M, Nishikiori N, Chiba H, Kojima T, Sawada N: Epigenetic silencing of occludin promotes tumorigenic and metastatic properties of cancer cells via modulations of unique sets of apoptosis-associated genes. Cancer Res 2006, 66(18):9125-9133.
46. Di Cello F, Cope L, Li H, Jeschke J, Wang W, Baylin SB, Zahnow CA Methylation of the claudin 1 promoter is associated with loss of expression in estrogen receptor positive breast cancer. PLoS One 2013, 8(7):e68630.

47. Corberand J, Laharrague P, Nguyen F, Dutau G, Fontanilles M, Gleizes B, Gyrard E: In vitro effect of tobacco smoke components on the functions of normal human polymorphonuclear leukocytes. Infect Immun 1980, 30(3):649-655.

48. Kim SR, Wipfli H, Avila-Tang E, Samet JM, Breysse PN: Method validation for measurement of hair nicotine level in nonsmokers. Biomed Chromatogr 2009, 23(3):273-279.

49. Sivaraman L, Stephens LC, Markaverich BM, Clark JA, Krnacik S, Conneely OM, O'Malley BW, Medina D: Hormone-induced refractoriness to mammary carcinogenesis in Wistar-Furth rats. Carcinogenesis 1998 19(9):1573-1581.

50. Tsai HC, Li H, Van Neste L, Cai Y, Robert C, Rassool FV, Shin JJ, Harbom KM, Beaty R, Pappou E, Harris J, Yen RW, Ahuja N, Brock MV, Stearns V, FellerKopman D, Yarmus LB, Lin YC, Welm AL, Issa JP, Minn I, Matsui W, Jang YY, Sharkis SJ, Baylin SB, Zahnow CA: Transient low doses of DNA-demethylating agents exert durable antitumor effects on hematological and epithelial tumor cells. Cancer Cell 2012, 21(3):430-446.

doi:10.1186/1476-4598-12-90

Cite this article as: Di Cello et al:: Cigarette smoke induces epithelial to mesenchymal transition and increases the metastatic ability of breast cancer cells. Molecular Cancer 2013 12:90.

\section{Submit your next manuscript to BioMed Central and take full advantage of:}

- Convenient online submission

- Thorough peer review

- No space constraints or color figure charges

- Immediate publication on acceptance

- Inclusion in PubMed, CAS, Scopus and Google Scholar

- Research which is freely available for redistribution 